\title{
Cardiovascular Endocrinology: Evolving Concepts and Updated Epidemiology of Relevant Diseases
}

\author{
Fahimeh Varzideh ${ }^{1,2}$, Urna Kansakar ${ }^{1,2}$, Stanislovas S. Jankauskas ${ }^{1,2}$, \\ Jessica Gambardella ${ }^{1,3}$ and Gaetano Santulli ${ }^{1,2,3^{*}}$ \\ 1 Department of Medicine, Division of Cardiology, Wilf Family Cardiovascular Research Institute, Einstein Institute for Aging \\ Research, Albert Einstein College of Medicine, New York, NY, United States, ${ }^{2}$ Department of Molecular Pharmacology, \\ Einstein-Mount Sinai Diabetes Research Center (ES-DRC), Fleischer Institute for Diabetes and Metabolism (FIDAM), Einstein \\ Institute for Neuroimmunology and Inflammation, Albert Einstein College of Medicine, New York, NY, United States, \\ ${ }^{3}$ Department of Advanced Biomedical Science, "Federico II" University, and International Translational Research and Medical \\ Education (ITME) Consortium, Naples, Italy
}

Keywords: cardiometabolism, diabetes mellitus, endocrine hypertension, HFpEF, insulin resistance, metabolic syndrome, NAFLD, uremic cardiomyopathy

\section{WHAT IS CARDIOVASCULAR ENDOCRINOLOGY?}

We created the new Cardiovascular Endocrinology section of Frontiers in Endocrinology as the perfect home for high-quality research across all aspects of cardiovascular endocrinology. This interdisciplinary forum will solicit significant advances in areas including, but not limited to:

Edited and reviewed by: Jeff M. P. Holly, University of Bristol, United Kingdom

*Correspondence: Gaetano Santulli gsantulli001@gmail.com

Specialty section: This article was submitted to Cardiovascular Endocrinology, a section of the journal

Frontiers in Endocrinology

Received: 08 September 2021 Accepted: 14 September 2021 Published: 05 October 2021

Citation:

Varzideh F, Kansakar U, Jankauskas SS, Gambardella J and Santulli G (2021)

Cardiovascular Endocrinology: Evolving Concepts and Updated Epidemiology of Relevant Diseases.

Front. Endocrinol. 12:772876. doi: 10.3389/fendo.2021.772876
- Cross-talk between the cardiovascular system and other organs and systems, such as kidney, lungs, thyroid, bone, skeletal muscle, gastrointestinal system, and nervous system (1);

- Involvement of the heart in systemic disorders;

- Autonomic regulation of the heart and the cardiovascular system;

- Stem cell mediated cardiovascular protection;

- Functional roles of hormones, regulatory peptides, and non-coding RNAs produced by (or actin on) the cardiovascular system (2-6).

To give to our Readers an idea of the burden of cardiovascular endocrinology in the clinical scenario, in this inaugural Editorial, we briefly discuss the current epidemiology of some disorders that perfectly fit within the definition of cardiovascular endocrinology (and therefore within the scope of this new Journal): endocrine hypertension, heart failure with preserved ejection fraction (HFpEF), metabolic syndrome, non-alcoholic fatty liver disease (NAFLD), and uremic cardiomyopathy.

\section{ENDOCRINE HYPERTENSION}

Based on conservative estimates, secondary hypertension affects 5-10\% of the general hypertensive population, but could be more common than currently recognized (7). More than $50 \%$ of children and $\sim 30 \%$ of young adults ( $<40$-year-old) who present with hypertension have a secondary cause, and such secondary causes are broadly categorized into renal and endocrine causes (8). We briefly report below the main endocrine causes of endocrine hypertension. 
Adrenal-dependent causes include primary aldosteronism [which prevalence has been underestimated for decades and has been recently shown to be $\sim 22 \%$ in patients with resistant hypertension (9)], Cushing syndrome ( $10-15$ per million are affected by the endogenous form, whereas iatrogenic forms are way more common and largely underestimated), Apparent mineralocorticoid excess (AME)/11ß-hydroxysteroid dehydrogenase deficiency (an extremely rare disease, also known as Ulick Syndrome, with fewer than 100 cases reported hitherto, resulting from an impaired activity of the enzyme HSD11B2, which normally inactivates cortisol), pheochromocytoma and sympathetic paraganglioma (prevalence: 20-60 per 10.000 patients who present with hypertension) (10).

Parathyroid-dependent causes are essentially represented by hyperparathyroidism (incidence: 4.03 per 10.000 in females and 1.37 in males). Pituitary-dependent causes include Cushing disease due to excessive ACTH secretion and acromegaly (prevalence: 5070 per million). Other mechanisms leading to endocrine hypertension include secondary hyperaldosteronism (for instance due to renovascular hypertension) and thyroid-dependent causes (both hypothyroidism and hyperthyroidism) (11).

\section{HFpEF}

Several studies estimate that as many as $40-60 \%$ of patients with heart failure (HF) have a normal ( $\geq 50 \%)$ LVEF (12). The proportion of patients with HF who have HFpEF is higher in older adults and appears to be increasing by about $1 \%$ annually relative to that of HF with reduced ejection fraction (HFrEF) (13). Most patients with HFpEF display normal left ventricular volumes and evidence of diastolic dysfunction, such as elevated filling pressures at rest or with exertion.

The pathophysiological understanding of HFpEF is still limited. Recent reports have shown that many HFpEF patients exhibit signs of non-resolving inflammation, endothelial dysfunction, insulin resistance, hyperlipidemia, and multiorgan defects (14). At a cellular level, cardiomyocytes in patients with HFpEF are thicker and shorter than normal cells, collagen content is increased, and recent histologic evaluations have revealed reductions in myocardial capillary density alongside lymphatic dysfunction (15). Furthermore, substantial evidence indicates that obesityrelated HFpEF may result from increased mineralocorticoid signaling, adipokines imbalance, and neprilysin overactivity (16).

\section{METABOLIC SYNDROME}

There are several definitions for metabolic syndrome; the one elaborated by the National Cholesterol Education Program (NCEP) Adult Treatment Panel III (ATPIII) is one of the most widely used, confirming the diagnosis in presence of any three of the following five traits:

-Abdominal obesity, defined as a waist circumference $\geq 102 \mathrm{~cm}$ (40 in) in men and $\geq 88 \mathrm{~cm}$ (35 in) in females;

-Blood pressure $\geq 130 / 85 \mathrm{mmHg}$ or drug treatment for hypertension; -Fasting plasma glucose $(\mathrm{FPG}) \geq 100 \mathrm{mg} / \mathrm{dL}$ (5.6 mmol/L) or drug treatment for hyperglycemia or diabetes;
-Serum triglycerides $\geq 150 \mathrm{mg} / \mathrm{dL}(1.7 \mathrm{mmol} / \mathrm{L})$ or drug treatment for hypertriglyceridemia;

-Serum high-density lipoprotein (HDL) cholesterol $<40 \mathrm{mg} / \mathrm{dL}$ $(1 \mathrm{mmol} / \mathrm{L})$ in males and $<50 \mathrm{mg} / \mathrm{dL}(1.3 \mathrm{mmol} / \mathrm{L})$ in females or drug treatment for low HDL cholesterol.

Metabolic syndrome has become increasingly prevalent in the last years. According to data from the National Health and Nutrition Examination Survey (NHANES) 2011 to 2016 database, 34.7 percent of participants met the above criteria compared with 22 percent in NHANES III (1988 to 1994); prevalence was $19.5 \%$ among those aged 20 to 39 years and increased to $48.6 \%$ among those aged at least 60 years (17).

\section{NAFLD}

NAFLD refers to the presence of hepatic steatosis when no other causes for secondary hepatic fat accumulation are present. It represents the most common liver disorder in industrialized countries, with a prevalence of 10 to $46 \%$ in the United States, and 6 to 35\% (median 20\%) worldwide. The diagnosis of NAFLD requires evidence (by imaging or histology) of hepatic steatosis and the exclusion of secondary causes of hepatic fat accumulation, including steatogenic medication (e.g. corticosteroids, methotrexate, amiodarone), viral infections (e.g. hepatitis C), or hereditary disorders (e.g. alpha-1 antitrypsin deficiency, Wilson's disease); moreover, daily alcohol consumption must not exceed $30 \mathrm{~g}$ for men and $20 \mathrm{~g}$ for women.

While metabolic syndrome is a known risk factor for cardiovascular disease and is common in NAFLD patients, NAFLD itself may be independently associated with cardiovascular disease (18). The underlying mechanisms linking NAFLD to cardiovascular disease are very complex and involve a number of different pathways, including insulin resistance, endothelial dysfunction, fibrosis, and alterations in gut microbiota (19).

\section{UREMIC CARDIOMYOPATHY}

The burden of cardiovascular disease in patients with end-stage renal disease is significant, with mortality from cardiovascular disease 15 to 30 times higher than the general population. Uremic cardiomyopathy is classically characterized by diastolic dysfunction in association with myocardial fibrosis and left ventricular hypertrophy in patients with chronic kidney disease.

The prevalence of HF in patients with chronic kidney disease populations increases with age, is markedly more common in dialysis patients (prevalence: $31-36 \%$ ) than in those with normal kidney function (prevalence: 1.8-4.4\%), and is inversely proportional to the estimated glomerular filtration rate.

Uremic cardiomyopathy may manifest as a result of hemodynamic overload (both pressure and volume), and a systemic uremic state. Alterations in mineral metabolism, coronary microvascular dysfunction, and the accumulation of substances such as endothelin, parathyroid hormone, tumor necrosis factor alpha, interleukin- $1 \alpha$ and interleukin-6, endogenous cardiotonic steroids as cardenolides (oubain and 
digoxin) and bufadienolides (marinobufagenin and proscillaridin A) contribute to the pathogenesis of uremic cardiomyopathy (20).

\section{AUTHOR CONTRIBUTIONS}

GS conceived the paper structure, searched for information, and wrote the paper. FV, UK, SSJ, and JG searched for information and wrote the paper. All authors contributed to the article and approved the submitted version.

\section{REFERENCES}

1. Funder JW. Cardiovascular Endocrinology: Into the New Millennium. Trends Endocrinol Metab (2001) 12(7):283-5. doi: 10.1016/S1043-2760(01)00443-X

2. Bradley CA. Cardiovascular Endocrinology: Long-Term Safety of Growth Hormone. Nat Rev Endocrinol (2018) 14(1):3. doi: 10.1038/nrendo.2017.155

3. Auchus RJ. Classics in Cardiovascular Endocrinology: Aldosterone Action Beyond Electrolytes. Endocrinology (2016) 157(2):429-31. doi: 10.1210/ en.2015-2061

4. Goetze JP, Albrethsen J. Adropin: A New Regulatory Peptide in Cardiovascular Endocrinology. Regul Pept (2014) 190-191:41-2. doi: 10.1016/j.regpep. 2014.04.002

5. Twickler TB, Cramer MJ. Heart Failure and Cardiovascular Endocrinology: Heart and Hormones. Neth Heart J (2004) 12(10):441-2.

6. Musunuru K, Kathiresan S. Cardiovascular Endocrinology: Is ANGPTL3 the Next PCSK9? Nat Rev Endocrinol (2017) 13(9):503-4. doi: 10.1038/ nrendo.2017.88

7. Yang J, Shen J, Fuller PJ. Diagnosing Endocrine Hypertension: A Practical Approach. Nephrol (Carlton) (2017) 22(9):663-77. doi: 10.1111/nep.13078

8. Koch C, Papadopoulou-Marketou N, Chrousos GP. Overview of Endocrine Hypertension. In: Feingold KR, Anawalt B, Boyce A, Chrousos G, de Herder WW, Dhatariya K, Dungan K, Grossman A, Hershman JM, Hofland J, et al. editors. Endotext. South Dartmouth (MA) (2000).

9. Brown JM, Siddiqui M, Calhoun DA, Carey RM, Hopkins PN, Williams GH, et al. The Unrecognized Prevalence of Primary Aldosteronism: A Cross-Sectional Study. Ann Intern Med (2020) 173(1):10-20. doi: 10.7326/M20-0065

10. Lenders JWM, Kerstens MN, Amar L, Prejbisz A, Robledo M, Taieb D, et al. Genetics, Diagnosis, Management and Future Directions of Research of Phaeochromocytoma and Paraganglioma: A Position Statement and Consensus of the Working Group on Endocrine Hypertension of the European Society of Hypertension. J Hypertens (2020) 38(8):1443-56. doi: 10.1097/HJH.0000000000002438

11. Carvajal CA, Tapia-Castillo A, Fardella CE. Extending the Endocrine Hypertension Spectrum: Novel Nonclassic Apparent Mineralocorticoid Excess. Endocrine (2021). doi: 10.1007/s12020-021-02783-1

12. Clark KAA, Velazquez EJ. Heart Failure With Preserved Ejection Fraction: Time for a Reset. JAMA (2020) 324(15):1506-8. doi: 10.1001/jama.2020.15566

13. Tsao CW, Lyass A, Enserro D, Larson MG, Ho JE, Kizer JR, et al. Temporal Trends in the Incidence of and Mortality Associated With Heart Failure With Preserved and Reduced Ejection Fraction. JACC Heart Fail (2018) 6(8):67885. doi: 10.1016/j.jchf.2018.03.006

\section{FUNDING}

The Santulli's Lab is supported in part by the National Institutes of Health (NIH: R01-DK123259, R01-HL146691, R01DK033823, R01-HL159062, R56-AG066431, T32-HL144456, and R00-DK107895, to GS), by the Irma T. Hirschl and Monique Weill-Caulier Trusts (to GS) and by the American Heart Association (AHA-21POST836407 to SSJ and AHA20POST35211151 to JG).

14. Tourki B, Halade GV. Heart Failure Syndrome With Preserved Ejection Fraction Is a Metabolic Cluster of Non-Resolving Inflammation in Obesity. Front Cardiovasc Med (2021) 8:695952. doi: 10.3389/fcvm.2021. 695952

15. Cuijpers I, Simmonds SJ, van Bilsen M, Czarnowska E, Gonzalez Miqueo A, Heymans S, et al. Microvascular and Lymphatic Dysfunction in HFpEF and Its Associated Comorbidities. Basic Res Cardiol (2020) 115(4):39. doi: 10.1007/s00395-020-0798-y

16. Oh A, Okazaki R, Sam F, Valero-Munoz M. Heart Failure With Preserved Ejection Fraction and Adipose Tissue: A Story of Two Tales. Front Cardiovasc Med (2019) 6:110. doi: 10.3389/fcrm.2019.00110

17. Hirode G, Wong RJ. Trends in the Prevalence of Metabolic Syndrome in the United States, 2011-2016. JAMA (2020) 323(24):2526-8. doi: 10.1001/ jama.2020.4501

18. Ma J, Hwang SJ, Pedley A, Massaro JM, Hoffmann U, Chung RT, et al. BiDirectional Analysis Between Fatty Liver and Cardiovascular Disease Risk Factors. J Hepatol (2017) 66(2):390-7. doi: 10.1016/j.jhep.2016.09.022

19. Kasper P, Martin A, Lang S, Kutting F, Goeser T, Demir M, et al. NAFLD and Cardiovascular Diseases: A Clinical Review. Clin Res Cardiol (2021) 110 (7):921-37. doi: 10.1007/s00392-020-01709-7

20. Wang X, Shapiro JI. Evolving Concepts in the Pathogenesis of Uraemic Cardiomyopathy. Nat Rev Nephrol (2019) 15(3):159-75. doi: 10.1038/s41581018-0101-8

Conflict of Interest: The authors declare that the research was conducted in the absence of any commercial or financial relationships that could be construed as a potential conflict of interest.

Publisher's Note: All claims expressed in this article are solely those of the authors and do not necessarily represent those of their affiliated organizations, or those of the publisher, the editors and the reviewers. Any product that may be evaluated in this article, or claim that may be made by its manufacturer, is not guaranteed or endorsed by the publisher.

Copyright (c) 2021 Varzideh, Kansakar, Jankauskas, Gambardella and Santulli. This is an open-access article distributed under the terms of the Creative Commons Attribution License (CC BY). The use, distribution or reproduction in other forums is permitted, provided the original author(s) and the copyright owner(s) are credited and that the original publication in this journal is cited, in accordance with accepted academic practice. No use, distribution or reproduction is permitted which does not comply with these terms. 